\title{
A Randomized Controlled Double-Blind Comparative Study between Bupivacaine 0.25\% Plus Fentanyl and Bupivacaine $0.25 \%$ Plus Dexmedetomidine for Caudal Epidural Postoperative Analgesia in Pediatric Lower Abdominal and Urogenital Surgeries in Indian Genotype
}

\author{
Rajashree Godbole ${ }^{1}$ Jasmeet Gill ${ }^{1}$ Brishnik Bhattacharya ${ }^{1}$ Shashank Shrotriya ${ }^{2}$ \\ Siddhartha Shrivastava ${ }^{3}$ Abhilash Bandari ${ }^{1}$ \\ ${ }^{1}$ Department of Anesthesiology, KEM Hospital, Pune, \\ Maharashtra, India \\ 2Department of Pediatric Surgery, KEM Hospital, Pune, \\ Maharashtra, India \\ ${ }^{3}$ Department of Otorhinolaryngology, KEM Hospital, \\ Pune, Maharashtra, India

\begin{abstract}
Address for correspondence Rajashree Godbole, MD, Department of Anesthesiology, KEM Hospital, Pune 411011, Maharashtra, India (e-mail: rajashree.godbole@gmail.com).
\end{abstract}

Int J Recent Surg Med Sci 2020;6:30-37

\begin{abstract}
Objectives This study aimed to clinically evaluate and compare the efficacy of caudal epidural bupivacaine in prolonging the postoperative analgesia, with adjuvants like fentanyl or dexmedetomidine among children of Indian genotype.

Materials and Methods A prospective double-blind randomized comparative study. The study population of 68 patients of Indian phenotype were randomly taken from a random number table and divided into two groups with 34 patients in each group. They received single shot caudal epidural blocks, with group A receiving $0.75 \mathrm{~mL} / \mathrm{kg}$ of $0.25 \%$ bupivacaine $+1 \mathrm{mcg} / \mathrm{kg}$ fentanyl, group B receiving $0.75 \mathrm{~mL} / \mathrm{kg}$ of $0.25 \%$ bupivacaine $+1 \mathrm{mcg} / \mathrm{kg}$ dexmedetomidine. Global Assessment of anesthesia, defined as the time from caudal injection to the first administration of rescue analgesia, will be recorded for both the groups.

Results The addition of either fentanyl or dexmedetomidine as adjuvants in caudal block provided excellent postoperative analgesia, and sedation was significantly longer duration with dexmedetomidine (18.0 hours) than fentanyl (13.1 hours). We observed good hemodynamic stability in both the groups.

Conclusion Addition of dexmedetomidine over fentanyl to bupivacaine for caudal epidural analgesia in pediatric age group has multiple advantages like better control of

Keywords

- caudal epidural

- dexmedetomidine

- fentanyl

- pediatric lower abdominal surgeries intraoperative and postoperative hemodynamics, significantly longer duration of postoperative analgesia, lesser bleeding during surgery, and achieving good surgical satisfaction. As the children are pain-free, calm, quiet, and sedated but arousable, the parents' satisfaction is rewarding. The caudal epidural dose of $0.25 \%$ bupivacaine $0.75 \mathrm{~mL} / \mathrm{kg}$ with adjuvants like dexmedetomidine or fentanyl is effective for postoperative analgesia in lower abdominal surgeries and is without side effects among the Indian population.
\end{abstract}

(C)2020 Medical and Surgical Update Society
License terms

(요 (1) $\odot \circledast$ 


\section{Introduction}

Amongst all the challenges in anesthesiology, pediatric pain relief is the most challenging one. Pain perception in children is complex and difficult to assess. Pediatric pain relief has been the focus of continuous human efforts. Pain relief in pediatric patients has been misunderstood, underdiagnosed, and treated inadequately. The reason being the misbelief that children do not perceive pain to the same degree as adults, experience difficulty in distinguishing pain from hunger or fear, face increased risk of opioid-induced respiratory depression, and suffer fear of opioid addiction.

Inadequate pain relief in pediatric patients may lead to long-term psychological effects like disrupted sleep and eating, harmful neuroendocrine responses, hyperalgesia, and allodynia. Postoperative pain can lead to noncooperation, continuous crying, and restlessness in children. Hence, it is always preferable to prevent the onset of pain rather than to relieve its existence. This is preemptive analgesia. ${ }^{1}$ The International Association for the study of Pain has defined pain as an unpleasant sensory and emotional experience associated with actual or potential tissue damage. ${ }^{2}$ This tissue damage leads to central sensitization and the development from acute to chronic pain. Actually, the term preemptive analgesia should be replaced by the term preventive analgesia. Multimodal analgesia or balanced analgesia is the best technique for postoperative pain relief. It combines drugs from different classes and analgesic techniques which target different mechanisms of pain, leading to their synergistic actions relieving maximum pain in low doses, thereby reducing the risks of adverse drug effects. ${ }^{3}$ The various modalities of analgesia commonly used are pharmacologicalnonsteroidal anti-inflammatory drugs (NSAIDs) and opioids, neuraxial blocks-epidural or intrathecal, intra-articular and wound infiltration with local anesthetic drug, peripheral nerve blocks. The NSAIDs are used to reduce the peripheral activation/sensitization of nociceptors, local anesthetics to block sensory inflow, and centrally acting opioids to prevent central sensitization throughout the postoperative period.

Caudal epidural block is one of the most popular, reliable, and safe techniques in pediatric analgesia which can provide analgesia for a variety of infra- and supraumblical surgical procedures. The increased fluidity of epidural fat in children leads to excellent blockade after caudal anesthesia in children up to 8 years of age. ${ }^{4}$ The main disadvantage of caudal analgesia is the short duration of action after a single injection. The use of caudal catheters to administer repeated doses or infusions of local anesthetics is not popular, partly because of concerns about infection. It also obviates the use of epidural catheter that entails higher risks of displacement and costs. Prolongation of caudal analgesia using a single-shot technique has been achieved by the addition of various adjuvants such as epinephrine, opioids, ketamine, and $\alpha 2$ agonists. $^{5}$

The use of adjuvants to local anesthetic has made it possible to prolong the duration of analgesia by up to 24 hours, and at the same time reducing the doses and thus the toxicity of local anesthetics. ${ }^{6}$ The addition of fentanyl or dexmedetomidine to local anesthetic solution has also been shown to enhance the duration and quality of central and peripheral nerve blocks. In view of the above, this study was undertaken to evaluate and compare the efficacy and safety of dexmeditomidine and fentanyl as adjuvants to local anesthetics when given caudally in children undergoing lower abdominal or perineal surgeries.

\section{Materials and Methods}

\section{Study Location}

This study was performed in the Department of Anesthesiology, KEM Hospital, Pune.

\section{Study Population}

Pediatric patients posted for lower abdominal surgeries like inguinal hernia repair, ureteric reimplantation, colostomy closure and urogenital surgeries between the age group of 1 to 8 years in accordance with the American Society of Anesthesiologists (ASA) grade I and II.

\section{Statistical Methods}

The data on categorical variables is presented as $\mathrm{n}$ (\% of cases). The data on continuous variables is presented as mean \pm standard deviation (SD) across two intervention groups. The statistical significance of difference of categorical variables across two intervention groups is tested using ChiSquare test or Fisher's exact probability test. The statistical significance of intergroup difference of mean of continuous variables is tested using independent sample " $t$ " (unpaired Student's "t" test) test after confirming the underlying normality assumption. $p$-Values less than 0.05 are considered to be statistically significant. All the hypotheses are formulated using two tailed alternatives against each null hypothesis (hypothesis of no difference). The entire data has been statistically analyzed using the Statistical Package for Social Sciences 34 (SPSS ver 16.0, Inc., Chicago, IL) for MS Windows.

\section{Sample Size Formula}

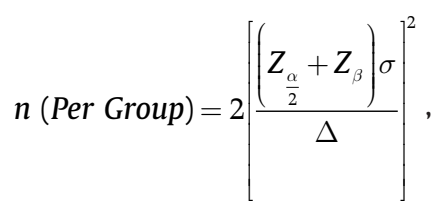

where $n=$ sample size (per group)

$Z_{\alpha / 2}=(1.96)$ for $95 \%$ confidence (i.e., $\left.=0.05\right)=1.96$

$Z_{\beta}=$ cutoff value for power $(1-\beta)=0.8$

$\sigma=$ common standard deviation (SD) of both the groups $=14.3$

$\Delta=$ mean difference to be detected $=10.0$ (duration of rescue analgesia)

$\Delta / \sigma=$ effect size in $\mathrm{SD}$ units $=0.70$

Sample size by using above formula $=31.15$ (minimum per group-31, i.e., total 62).

An additional $10 \%$ subjects will be included to cover for any potential dropouts who may materialize postoperatively due to reasons such as administration of antipyretics (in febrile children) which also have analgesic effect and 
hence would interfere with the trial results. Therefore, final sample size $=31.15+3.11=34.2(34$ per group, i.e., total 68$)$

The calculation of sample size is necessary to provide reliable answer to the research question, in order to not only estimate the length of study but also judge the feasibility of conducting the study within the planned budget.

\section{Study Design}

A prospective double-blind randomized comparative study. Randomization is performed with the help of the random number table method. A double-blind study-subjects were unaware of the adjuvant used. The drug was prepared by the attending anesthesiologist and was administered by the blinded primary investigator; intraoperative recording and postoperative assessment was also done by primary investigator.

\section{Inclusion Criteria}

Written informed consent, ASA grade I and II, age between 1 to 8 years, type of surgery: lower abdominal and urogenital surgeries, and weight 3 to $20 \mathrm{~kg}$.

\section{Exclusion Criteria}

Bleeding disorder, patient with known hypersensitivity to bupivacaine or fentanyl or dexmedetomidine, mentally retarded patients, and infection at the site of needle placement

\section{Study Intervention}

Group A: $0.75 \mathrm{~mL} / \mathrm{kg}$ of $0.25 \%$ bupivacaine $+1 \mathrm{mcg} / \mathrm{kg}$ fentanyl

Group B: $0.75 \mathrm{~mL} / \mathrm{kg}$ of $0.25 \%$ bupivacaine $+1 \mathrm{mcg} / \mathrm{kg}$ dexmedetomidine

Global assessment of anesthesia, defined as the time from caudal injection to the first administration of analgesia, was recorded for both the groups: Any side effects in terms of hemodynamic alterations, respiratory depression, vomiting, urinary retention, and sedation were noted.

\section{Preanesthetic Assessment}

The cases were selected after a thorough preanesthetic assessment, including detailed history, clinical examination and relevant laboratory investigations. The spine was examined for any evidence of sacral anomalies, skin infection, bony landmarks, movements, and previous operations. Any child with a suspicion of infection over the sacral region and those with obvious bony anomalies of the sacrum were excluded from the study.

\section{Investigations}

Hemogram with prothrombin time (PT) and partial thromboplastin time (PTT), urine-routine/microscopic examination, bleeding time and clotting time.

Method: All patients were kept nil per orally 6 hours for solid food, 4 hours for breast milk, and 2 hours for clear liquids before surgery. Premedication was injected glycopyrolate $5 \mathrm{mcg} / \mathrm{kg}$ intramuscularly.

\section{Anesthesia Technique}

Induction was done with inhalational induction of general anesthesia using sevoflurane, and IV access was established. Vecuronium $0.1 \mathrm{mg} / \mathrm{kg}$ was intravenously injected to facilitate endotracheal intubation. Fentanyl $1 \mathrm{mcg} / \mathrm{kg}$ was injected. Maintenance of anesthesia was done with oxygen + nitrous oxide + sevoflurane. Vecuronium bromide was injected for maintenance of muscle relaxation. Caudal block was performed after induction and before the start of surgery, using standard techniques. To facilitate blinding, drug was prepared by project guide using random number table to select subjects for each group, and it was administered by primary investigator who was unaware of the additive use and intraoperative monitoring. The patient was monitored using standard monitoring, that is, electrocardiogram (ECG), heart rate, pulse oximetry, and noninvasive blood pressure during the course of surgery. Intravenous fluids were given as per requirement according to Holliday Segar formula. The neuromuscular blockade was reversed by injecting Neostigmine $50 \mathrm{mcg} / \mathrm{kg}$ and inj. glycopyrrolate $8 \mathrm{mcg} / \mathrm{kg}$ at the end of surgery.

\section{Postoperative Monitoring}

Postoperative monitoring was done in the postanesthesia care unit (PACU). Modified Bromage scale was used for monitoring of motor power. Patients were shifted to the ward after 3 hours when the Modified Bromage score was 0 or 1 and monitored in the ward using a standard proforma for the next 24 hours. The assessment of pain relief was done by using the objective pain scale. Patients were observed for other complications, namely, nausea, vomiting, respiratory depression, sedation, hypotension and bradycardia, sedation score, and urinary retention. At the onset of pain, rescue analgesia was given and the total duration of analgesia was noted. The rescue analgesia was given when pain score was more than or equal to 6 . Paracetamol $15 \mathrm{mg} / \mathrm{kg}$ intravenously injected as rescue analgesic (- Table $\mathbf{1}$ ).

\section{Ramsay Sedation Score}

$1=$ anxious, agitated, or restless

$2=$ cooperative, oriented, and tranquil

$3=$ responsive to commands

4 = asleep, but with brisk response to light, glabelar tap, or loud auditory stimulus

5 = asleep, sluggish response to glabelar tap, or auditory stimulus

6 = asleep, no response. Patients will be also asked about recalling of intraoperative events or any sign of awareness.

\section{Results}

The demographic parameters, for example, age, sex, weight and type of surgery were comparable in both the groups.

The mean duration of procedure was $75.4 \pm 25.7$ minutes in group A and $72.4 \pm 28.2$ minutes in group B. The distribution of mean duration of procedure among the cases studied did not differ significantly between two study groups $(p>0.05)$. 
Table 1 Objective pain scale

\begin{tabular}{|c|c|c|}
\hline Observation & Criteria & Points \\
\hline \multirow[t]{3}{*}{ Blood Pressure } & $\pm 10 \%$ preoperative & 0 \\
\hline & >20\% preoperative & 1 \\
\hline & $\begin{array}{l}>30 \% \\
\text { premedication }\end{array}$ & 2 \\
\hline \multirow[t]{3}{*}{ Crying } & Not crying & 0 \\
\hline & $\begin{array}{l}\text { Crying but } \\
\text { responds to TLC }\end{array}$ & 1 \\
\hline & $\begin{array}{l}\text { Crying not } \\
\text { responding to TLC }\end{array}$ & 2 \\
\hline \multirow[t]{3}{*}{ Movement } & None & 0 \\
\hline & Restless & 1 \\
\hline & Thrashing & 2 \\
\hline \multirow[t]{3}{*}{ Agitation } & Patient asleep & 0 \\
\hline & Mild & 1 \\
\hline & Hysterical & 2 \\
\hline \multirow[t]{3}{*}{ Posture } & No special posture & 0 \\
\hline & $\begin{array}{l}\text { Flexing legs and } \\
\text { thighs }\end{array}$ & 1 \\
\hline & $\begin{array}{l}\text { Holding scrotum } \\
\text { and thighs }\end{array}$ & 2 \\
\hline \multirow{3}{*}{$\begin{array}{l}\text { Complaints of pain } \\
\text { (where appropriate } \\
\text { by age) }\end{array}$} & Asleep/no pain & 0 \\
\hline & Cannot localize & 1 \\
\hline & Can localize & 2 \\
\hline
\end{tabular}

Abbreviation: TLC, tender loving care.

Note: Maximum score: 12; minimum score: 0 .

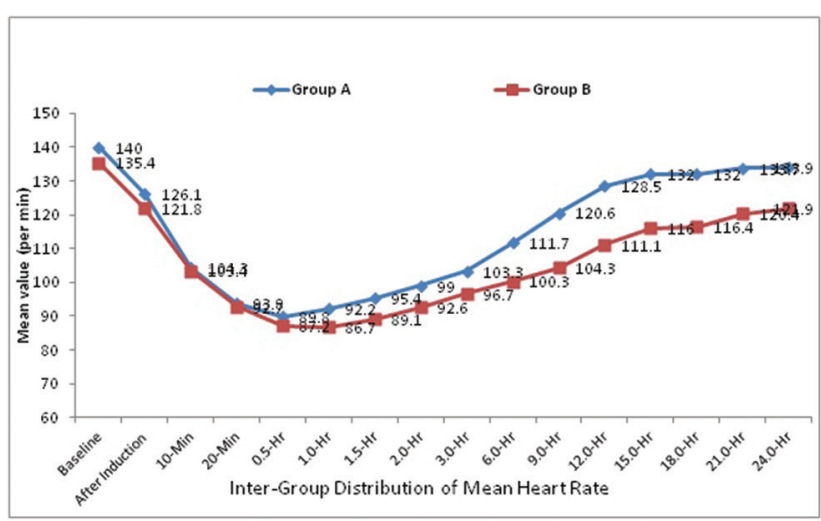

Fig. 1 Intergroup comparison of mean heart rate.

In our study, 23 patients in group A and 26 patients in group $B$ were catheterized. The remaining patients passed urine in 3 to 4 hours postoperatively. No patient required catheterization (-Fig. 1).

The distribution of mean heart rate at baseline, after induction, at incision, 10 minutes, 20 minutes and 0.5 hours did not differ significantly between two study groups ( $p>0.05$ for all).

The distribution of mean heart rate at 1.0 hour, 1.5 hours, 2.0 hours, 3.0 hours, 6.0 hours, 9.0 hours, 12.0 hours, 15.0 hours, 18.0 hours, 21.0 hours, and 24.0 hours was

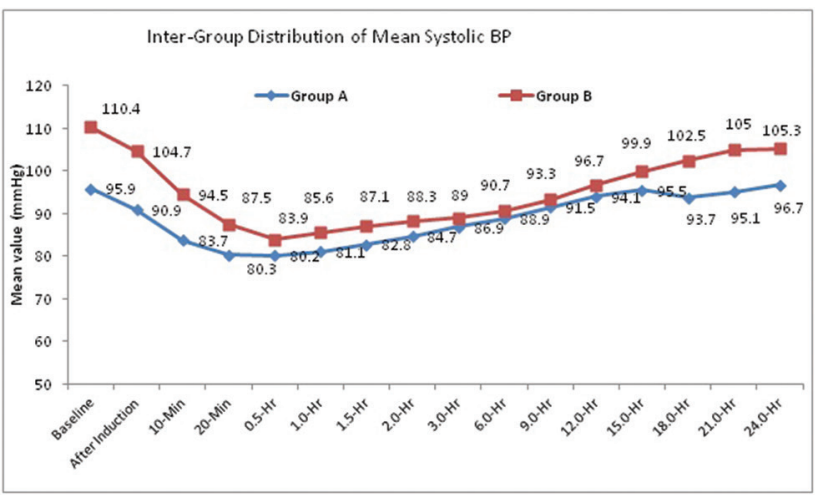

Fig. 2 Intergroup distribution of mean systolic blood pressure (BP).

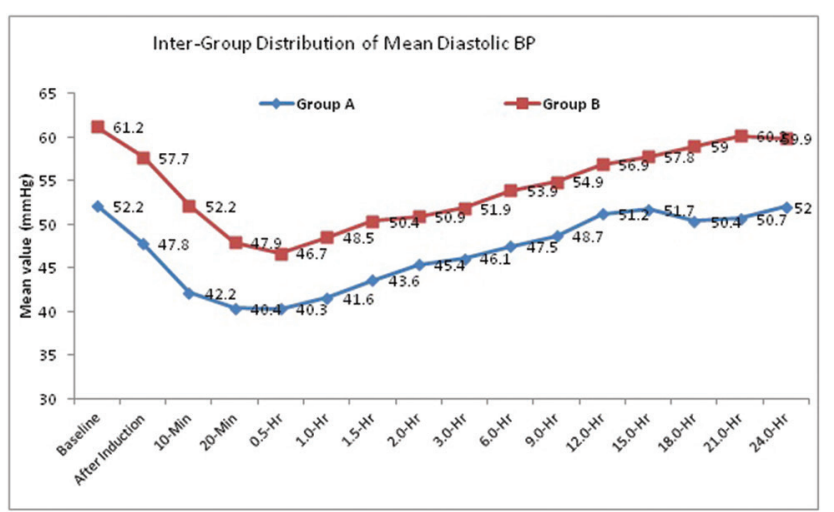

Fig. 3 Intergroup comparison of mean diastolic blood pressure (BP).

significantly higher in group A compared with group B $(p<0.05$ for all) ( - Fig. 1).

The distribution of mean systolic BP at baseline, after induction, 10 minutes, 20 minutes, 0.5 hour, 1.0 hour, 1.5 hours, 2.0 hours, 15.0 hours, 18.0 hours, 21.0 hours, and 24.0 hours is significantly higher in group B compared with group $\mathrm{A}$ ( $p<0.05$ for all). The distribution of mean systolic BP at 3.0 hours, 6.0 hours, 9.0 hours and 12.0 hours, that is in the immediate postoperative period, did not differ significantly between two study groups.( $p>0.05$ for all). The systolic BP decreased by $24 \%$ of preoperative values in dexmedetomidine group and by $16 \%$ in fentanyl group, returning to near baseline levels at 24 hours in both the groups (-Fig. 2).

The distribution of mean diastolic BP at baseline, after induction, 10 minutes, 20 minutes, 0.5 hour, 1.0 hours, 1.5 hours, 2.0 hours, 3.0 hours, 6.0 hours, 9.0 hours, 12.0 hours, 15.0 hours, 18.0 hours, 21.0 hours, and 24.0 hours is significantly higher in group B compared with group A $(p<0.001$ for all). Fall in mean diastolic BP from preoperative $\mathrm{BP}$ to BP at 1 hour is $23.6 \%$ in group B and $22.7 \%$ in group A (-Fig. 3).

The distribution of mean pain score at 1.0 hour, 18.0 hours, 21.0 hours and 24.0 hours did not differ significantly between two study groups ( $p>0.05$ for all). The distribution of pain score at 1.5 hours, 2.0 hours, 3.0 hours, 6.0 hours, 9.0 hours, 12.0 hours, and 15.0 hours is significantly higher in group $A$ compared with group B ( $p<0.05$ for all) ( - Fig. 4 ). 


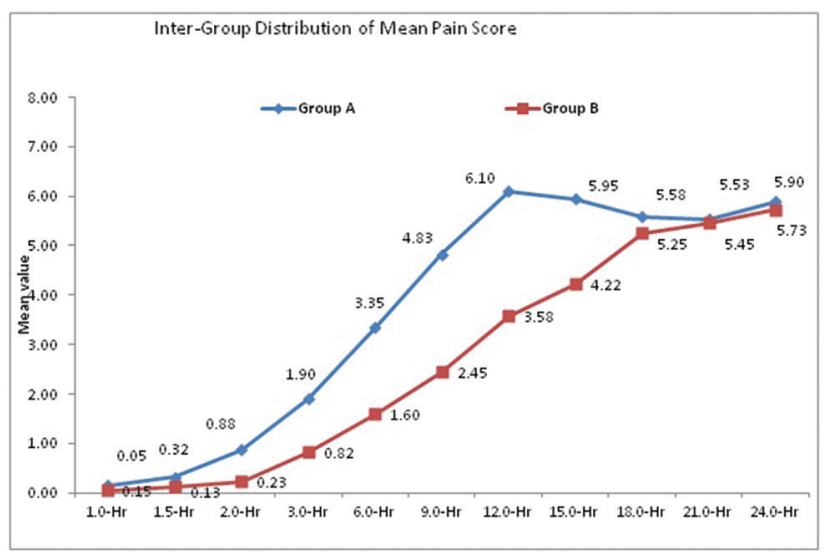

Fig. 4 Intergroup comparison of mean pain score.

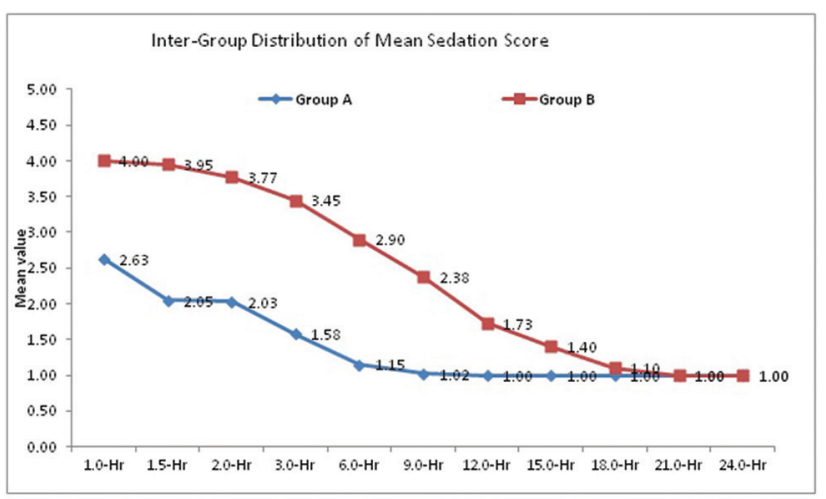

Fig. 5 Intergroup comparison of mean sedation score (Ramsay Score).

The distribution of mean sedation score 1.0 hour, 1.5 hours, 2.0 hours, 3.0 hours, 6.0 hours, 9.0 hours 12.0 hours, 15.0 hours, and 18.0 hours is significantly higher in group B compared with group A ( $p<0.05$ for all).

The distribution of mean sedation score at 21.0 hours and 24.0 hours did not differ significantly between two study groups ( $p>0.05$ for both) (-Fig. 5).

\section{Discussion}

Caudal block is safe, easy to perform in children, gives reliable results, and requires no expensive or special equipment. It is not associated with hemodynamic changes as seen with epidural in adults. Arousal after anesthesia is painless, making it very useful for day care surgery and anesthesia. Caudal blocks have very low incidence of serious complications (1 in 10,000). Serious complications include total spinal, infection, epidural hematoma, dysrhythmias, hypotension, seizures and cardiac arrest. For calculation of volume dosing of the caudally injected local anesthetic, Armitage scale guidelines were used. ${ }^{4}$ The caudally injected drug has cranial rebound which spreads the drug two spinal segments cranially. The cranial rebound mechanism has two phases: in phase 1, the epidural injection of the local anesthetic leads to increase in the epidural pressure forcing the cerebrospinal fluid (CSF) in the cranial direction. In phase 2 , the intracranial and spinal pressure gradient shifts the CSF in the caudal direction, forcing the local anesthetic drug to spread cranially. ${ }^{7,8}$ Consider this and the adjuvant we have taken ( $0.25 \%$ bupivacaine $0.75 \mathrm{~mL} / \mathrm{kg}$ ) as the caudal dose, although the recommended dose for lower abdominal surgeries is $1 \mathrm{~mL} / \mathrm{kg}$.

The difficulty of assessing and measuring pain in children, due to developmental, emotional and cognitive differences between adults and children, has, in part, been responsible for inadequate treatment of their pain. Pain assessment in children relies either on objective methods (observation of physiological and behavioral changes) or subjective methods (self-assessment). Observational assessment is inferior to self-assessment, but it is frequently the only method available in younger children. Objective pain score is a good tool for assessment of postoperative pain and need for analgesia. ${ }^{9}$

Clonidine and dexmedetomidine belong to $\alpha-2$ agonist group. But dexmedetomidine is a highly selective $\alpha$-2a agonist, having 1600 times more affinity for $\alpha$-2a receptors. It acts on $\alpha-2$ a and imidazoline type I receptors. The $\alpha-2$ receptors regulate the autonomic nervous and cardiovascular systems. They are located in the blood vessels where they cause vasoconstriction and in the sympathetic terminal where they inhibit norepinephrine release. This ultimately leads to fall in blood pressure and heart rate. Dexmedetomidine has got inherent analgesic, sedative, and anesthetic sparing properties which avoid the use of multiple drugs. ${ }^{10-12}$ It has minimal respiratory depressant effect with cardioprotection, neuroprotection and renoprotection. It is a highly selective $\alpha-2$ agonist compared with clonidine, eliminating the $\alpha$ - 1 receptor-induced side effects. ${ }^{13}$ Dexmedetomidine exerts sedative and analgesic sparing effect through central locus ceruleus in the dorsal horn of the spinal cord. ${ }^{11,14}$ Dexmedetomidine is equally useful for controlled hypotension. ${ }^{10,14}$

Fentanyl is a synthetic opioid, $\mu$ receptor agonist with rapid onset and short duration of action. It is a derivative of phenylpiperidine. Lipophilic opioids have got faster onset of actions and faster elimination compared with hydrophilic opioids. Opioids act as agonists through stereo-specific opioid receptors at presynaptic and postsynaptic sites in the central nervous system (CNS). Existence of the opioid in the ionized state appears to be necessary for strong binding at the anionic opioid receptor site. The principal effect of opioid receptor activation is a decrease in neurotransmission at the presynaptic site. Opioid receptors exist on the peripheral ends of primary afferent neurons, and their activation may either directly decrease neurotransmission or inhibit the release of excitatory neurotransmitters such as substance P. Placement of opioids in the epidural or subarachnoid space produces analgesia which is specific for visceral pain rather than somatic pain. Pruritus, nausea and vomiting, urinary retention, depression of ventilation, sedation, and CNS excitation are some of the common side effects of fentanyl. ${ }^{15}$

In our study, there is fall in mean heart rate, mean systolic and diastolic blood pressure in both the groups after caudal injection but none of our patients required treatment. This might be because of the premedication: inj glycopyrrolate and proper intravenous fluid replacement. The fall in blood 
pressure was more in fentanyl group in our study. The hemodynamics were stable in both the groups. We did not come across any side effects like nausea, vomiting, pruritus, etc. The mean pain score was high in fentanyl group till 15 hours which was comparable after that. The Ramsay sedation score was high in dexmedetomidine group till 18 hours.

Elfawal et al conducted a randomized double-blinded comparative study of dexmedetomidine and fentanyl as adjuvants to levobupivacaine for caudal analgesia in children undergoing lower limb orthopedic surgery. Group L (control) received $0.75 \mathrm{~mL} / \mathrm{kg}$ levobupivacaine $0.25 \%$ diluted in saline; group LD received $0.75 \mathrm{~mL} / \mathrm{kg}$ levobupivacaine $0.25 \%$ with dexmedetomidine $1 \mathrm{mcg} / \mathrm{kg}$, and group LF received $0.75 \mathrm{~mL} /$ $\mathrm{kg}$ levobupivacaine $0.25 \%$ with fentanyl $1 \mathrm{mcg} / \mathrm{kg}$. Results were comparable to our study in that dexmedetomidine was seen to provide a greater mean duration of analgesia when compared with fentanyl. However, the mean duration of analgesia for both groups was significantly lower than that observed in our study, being 8 hours and 5.5 hours, respectively, for dexmedetomidine group and fentanyl group. The disparity seen is probably due to the use of a different pain scale for evaluation in their study, that is, FLACC scale. ${ }^{16}$ This is a similar study like ours, with the only difference being that they have used levobupivacaine instead of bupivacaine.

Kannojia et al conducted a randomized controlled study for comparison of caudal dexmedetomidine and fentanyl when combined with bupivacaine in pediatric patients undergoing urogenital surgery. The three groups in their study were as follows: group $\mathrm{BD}(n=30)$ received $1 \mathrm{mcg} / \mathrm{kg}$ dexmedetomidine with $0.5 \mathrm{~mL} / \mathrm{kg}$ bupivacaine $0.25 \%$; group $\mathrm{BF}(n=30)$ received $1 \mathrm{mcg} / \mathrm{kg}$ fentanyl with $0.5 \mathrm{~mL} / \mathrm{kg}$ bupivacaine $0.25 \%$, and group B $(n=30)$ received $0.5 \mathrm{~mL} / \mathrm{kg}$ of bupivacaine $0.25 \%$ for caudal epidural analgesia. Hemodynamic parameters, Pediatric Anesthesia Emergence Delirium (PAED) score, Richmond agitation sedation scale (RASS), and Children's Hospital of Eastern Ontario Pain Scale (CHEOPS) were recorded immediate postoperatively and then regularly every hour for the next 12 hours. The mean heart rate and mean systolic and diastolic blood pressure changes over time were comparable to our study, with the group receiving dexmedetomidine showing lower intraoperative and postoperative mean heart rate, and mean systolic and diastolic blood pressure, than group which received fentanyl as additive. The duration of analgesia in dexmedetomidine group is 24 hours which is more comparable to our study ${ }^{17}$ The dose of bupivacaine in our study was $0.75 \mathrm{~mL} / \mathrm{kg}$.

Jarineshin et al compared dexmedetomidine and fentanyl with bupivacaine $0.25 \%$ in caudal block for postoperative pain relief in pediatric patients undergoing inguinal hernia repair. The groups in their study were: bupivacaine $0.25 \% 1 \mathrm{~mL} / \mathrm{kg}$, bupivacaine $0.25 \% 1 \mathrm{~mL} / \mathrm{kg}$ with dexmedetomidine $2 \mathrm{mcg} / \mathrm{kg}$, and bupivacaine $0.25 \% 1 \mathrm{~mL} / \mathrm{kg}$ with fentanyl $2 \mathrm{mcg} / \mathrm{kg}$. They concluded that the analgesia and sedation were prolonged for 24 hours and comparable in dexmedetomidine and fentanyl group compared with the other group. They noticed no side effects like hypotension, bradycardia, pruritus, nausea, vomiting, and urinary retention in their study.$^{18}$ In our study, the dose of bupivacaine is $0.75 \mathrm{~mL} / \mathrm{kg}$ instead of $1 \mathrm{~mL} / \mathrm{kg}$ in their study. The doses of dexmedetomidine and fentanyl in our study were $1 \mathrm{mcg} / \mathrm{kg}$ instead of $2 \mathrm{mcg} / \mathrm{kg}$ in their study.

The analgesia was prolonged till 18 hours in the dexmedetomidine group and 13.1 hours in the fentanyl group among the Indian population.

Al-Zaben et al conducted a randomized double-blinded study of caudal bupivacaine with two different doses of dexmedetomidine for postoperative analgesia in pediatric patients undergoing infra umbilical surgeries. The groups in their study were: group $1-0.25 \%$ bupivacaine $0.8 \mathrm{~mL} / \mathrm{kg}$, group two- $0.25 \%$ bupivacaine $0.8 \mathrm{~mL} / \mathrm{kg}$ with dexmedetomidine $1 \mathrm{mcg} / \mathrm{kg}$, and the $3 \mathrm{rd}$ group was $0.25 \%$ bupivacaine $0.8 \mathrm{~mL} / \mathrm{kg}$ with $2 \mathrm{mcg} / \mathrm{kg}$ dexmedetomidine. They concluded that the analgesia was comparable in in both the groups of dexmedetomodine. In the third group of dexmedetomidine $2 \mathrm{mcg} / \mathrm{kg}$, they noticed bradycardia, hypotension and urinary retention..$^{19}$ This study has comparable doses of bupivacaine as ours. Probably dexmedetomidine $1 \mathrm{mcg} / \mathrm{kg}$ dose is responsible for no complications in our study.

Goyal et al conducted a randomized double-blind study to evaluate the effects of dexmedetomidine as an adjuvant to bupivacaine in caudal analgesia in infraumbilical surgeries. The two groups were group A: $(0.25 \%)$ bupivacaine $1 \mathrm{~mL} / \mathrm{kg}+$ normal saline (NS) $1 \mathrm{ml}$, and group B: (0.25\%) bupivacaine $1 \mathrm{~mL} / \mathrm{kg}+1 \mathrm{mcg} / \mathrm{kg}$ dexmedetomidine in $1 \mathrm{~mL}$ NS. The patients were observed for hemodynamic stability, respiratory depression, and postoperative pain using FLACC pain scale for 24 hour postoperatively. They concluded that mean duration of effective analgesia in group A patients was $4.33 \pm 0.98$ hour versus $9.88 \pm 0.90$ hour in group $B$ patients. Furthermore the difference in mean FLACC score of both the groups was also statistically significant. Thus dexmedetomidine as adjuvant to bupivacaine increases duration of caudal analgesia and improves hemodynamic stability without an increase in adverse effects in children undergoing infraumbilical surgeries. ${ }^{20}$ These drugs as additives intensify the local anesthetic conduction block by blocking $A \delta$ and $C$ fibers, thereby causing local vasoconstriction and limiting the local anesthetic spread and $\alpha-2 a$ agonistic actions. ${ }^{20}$

Sengupta et al conducted a study to compare the postoperative analgesic efficacy of bupivacaine plus fentanyl (BF) and ropivacaine plus fentanyl (RF) by caudal epidural technique in pediatric infraumbilical surgeries. The two groups were group BF receiving bupivacaine $0.25 \%, 0.7 \mathrm{~mL} /$ $\mathrm{kg}$ with fentanyl $1 \mathrm{mcg} / \mathrm{kg}$ and group RF receiving ropivacaine $0.25 \%, 0.7 \mathrm{ml} / \mathrm{kg}$ with fentanyl $1 \mathrm{mcg} / \mathrm{kg}$. Assessment of pain was done using perioperative hemodynamics and any adverse effects were monitored at regular intervals. Time to rescue analgesia was $252.67 \pm 7.038$ minutes in bupivacaine fentanyl group and $286 \pm 10.780$ minutes in ropivacaine fentanyl group. The RF group experienced significantly longer duration of effective postoperative analgesia, with significantly shorter duration of motor blockade and lesser total analgesic requirement in comparison to the BF group. Hemodynamically, patients in both the groups were stable. They concluded that ropivacaine, with an equipotent 
analgesic efficacy and a lesser duration of motor block, can be used as an alternative to bupivacaine for pediatric postoperative pain care through the caudal route. ${ }^{21}$

Anand et al conducted a randomized, prospective, parallel group double-blinded study. The two groups in their study were-group $\mathrm{RD}(\eta=30)$ received $0.25 \%$ ropivacaine $1 \mathrm{~mL} / \mathrm{kg}$ with dexmedetomidine $2 \mathrm{mcg} / \mathrm{kg}$, making the volume to $0.5 \mathrm{~mL}$, and group $\mathrm{R}(\mathrm{\eta}=30)$ received $0.25 \%$ ropivacaine $\mathrm{ml} / \mathrm{kg}+0.5 \mathrm{~mL}$ NS. Behavior during emergence was rated with a 4-point scale, sedation with Ramsay's sedation scale, and pain assessed with FLACC pain score. The duration of postoperative analgesia recorded a median of 5.5 hours in Group $\mathrm{R}$ compared with 14.5 hours in Group RD, with a $p$-value of $<0.001$. Group R patients achieved a statistically significant higher FLACC score compared with Group RD patients. The difference between the means of mean sedation score, emergence behavior score, mean emergence time was statistically highly significant $(p<0.001)$. The perioperative hemodynamics were stable among both the groups. Thus, they concluded that caudal dexmedetomidine $(2 \mathrm{mcg} / \mathrm{kg}$ ) with $0.25 \%$ ropivacaine $(1 \mathrm{~mL} / \mathrm{kg}$ ) for pediatric lower abdominal surgeries achieved significant postoperative pain relief that resulted in a better quality of sleep and a prolonged duration of arousable sedation, and produced less incidence of emergence agitation following sevoflurane anesthesia. ${ }^{22}$ The duration of analgesia with dexmedetomidine $2 \mathrm{mcg} / \mathrm{kg}$ is less compared with our study.

Saini et al conducted a prospective randomized doubleblind study for comparison of caudal epidural clonidine with fentanyl as an adjuvant to ropivacaine $0.25 \%$ for postoperative analgesia in children undergoing various infraumbilical surgeries. The two groups were group RCropivacaine $(0.25 \%, 1 \mathrm{~mL} / \mathrm{kg})$ and clonidine $(2 \mathrm{mcg} / \mathrm{kg})$ and group RF-ropivacaine $(0.25 \%, 1 \mathrm{~mL} / \mathrm{kg})$ and fentanyl $(1 \mathrm{mcg} / \mathrm{kg})$ They observed that both groups were similar with respect to baseline hemodynamic parameters and duration of surgery. The analgesic properties and hemodynamics were also comparable in both groups $(p>0.05)$. The mean recovery time and Ramsay sedation score were significantly lower in group $\mathrm{RC}$ as compared with group RF ( $p<0.05)$. Side effects such as nausea, vomiting, and respiratory depression were seen only in group RF. Their study concluded that both clonidine ( $2 \mathrm{mcg} / \mathrm{kg}$ ) and fentanyl ( $1 \mathrm{mcg} / \mathrm{kg}$ ) can be used as an adjuvant to single-shot caudal epidural anesthesia using $0.25 \%$ ropivacaine for effective postoperative analgesia in children. The duration of pain relief with fentanyl was 600 to 720 minutes. $^{23}$ The duration of pain relief and hemodynamics with fentanyl are comparable in our study. The dose of ropivacaine is $1 \mathrm{~mL} / \mathrm{kg}$ instead of $0.75 \mathrm{~mL} / \mathrm{kg}$ in our study.

Khatavkar et al conducted a study to compare the caudal block characteristics of ropivacaine $0.25 \%$ with clonidine $1 \mathrm{mcg} / \mathrm{kg}$ versus ropivacaine $0.25 \%$ with fentanyl $1 \mathrm{mcg} / \mathrm{kg}$ in pediatric patients.Children were randomly allocated into two equal groups-group RF received $1 \mathrm{~mL} / \mathrm{kg}$ of ropivacaine $0.25 \%$ plus fentanyl $1 \mathrm{mcg} / \mathrm{kg}$ and group $\mathrm{RC}$ received $1 \mathrm{~mL} / \mathrm{kg}$ of ropivacaine $0.25 \%$ plus clonidine $1 \mathrm{mcg} / \mathrm{kg}$. Duration of analgesia, sedation score, and any side effects were noted. Duration of analgesia was 6 hours for fentanyl group and
15 hours for clonidine group. They came across no side effects. $^{24}$

Reddy and Gangadharaiah conducted a study to assess the efficacy, safety and duration of analgesia of equal volumes and concentrations of clonidine and dexmedetomidine as adjuvants to low volume and concentration of ropivacaine. They used $0.25 \%$ ropivacaine $0.5 \mathrm{~mL} / \mathrm{kg}+0.5 \mathrm{mcg} / \mathrm{kg}$ dexmedetomidine or clonidine. They observed that there was a statistically significant increased duration of analgesia with the dexmedetomidine group compared with clonidine group. The mean duration of analgesia in group receiving dexmedetomidine was $9.26 \pm 0.3$ hours, which is again significantly less than that observed in our study probably due to lesser dose of dexmedetomidine used here. ${ }^{25}$

\section{Conclusion}

We recommend the addition of dexmedetomidine over fentanyl to bupivacaine for caudal epidural analgesia in pediatric age group because of its multiple advantages like better control of intraoperative and postoperative hemodynamics, significantly longer duration of postoperative analgesia, lesser bleeding during surgery achieving good surgical satisfaction, almost no incidence of side effects compared with other adjuvants and cost-effectiveness because of less usage of other analgesic drugs. As the children are pain-free, calm, quiet, and sedated but arousable, the parents' satisfaction is rewarding. The caudal epidural dose of $0.25 \%$ bupivacaine $0.75 \mathrm{~mL} / \mathrm{kg}$ with adjuvants like dexmedetomidine or fentanyl is effective and adequate for postoperative analgesia in pediatric lower abdominal surgeries and is without side effects among the Indian population.

\section{Conflict of Interest}

None declared.

\section{References}

1 Dahl JB, Kehlet H. Preventive analgesia. Curr Opin Anaesthesiol 2011;24(3):331-338

2 Srouji R, Ratnapalan S, Schneeweiss S. Pain in children: assessment and nonpharmacological management. Int J Pediatr 2010;2010:474838

3 Polomano RC, Fillman M, Giordano NA, Vallerand AH, Nicely KL, Jungquist CR. Multimodal analgesia for acute postoperative and trauma -related pain. Am J Nurs 2017;117(3, Suppl 1):S12-S26

4 Miller RD. Miller's Anaesthesia. 8th ed. Philadelphia: Elsevier Saunders; 1600

5 Lönnqvist PA. Adjuncts to caudal block in children-Quo vadis? Br J Anaesth 2005;95(4):431-433

6 Caudal Epidural Block A, Review. Anaesthesia Today. December 19, 2010

7 Lundblad M, Eksborg S, Lönnqvist PA. Secondary spread of caudal block as assessed by ultrasonography. $\mathrm{Br}$ J Anaesth 2012;108(4):675-681

8 Wiegele M, Marhofer P, Lönnqvist PA. Caudal epidural blocks in paediatric patients: a review and practical considerations. Br J Anaesth 2019;122(4):509-517

9 Tandon M, Singh A, Saluja V, Dhankhar M, Pandey CK, Jain P. Validation of a new "objective pain score" vs. "numeric rating scale" for the evaluation of acute pain: a comparative study. Anesth Pain Med 2016;6(1):e32101 
10 Naaz S, Ozair E. Dexmedetomidine in current anaesthesia practice- a review. J Clin Diagn Res 2014;8(10):GE01-GE04

11 Kaur M, Singh PM. Current role of dexmedetomidine in clinical anesthesia and intensive care. Anesth Essays Res 2011;5(2): 128-133

12 McCallum JB, Boban N, Hogan Q, Schmeling WT, Kampine JP, Bosnjak ZJ. The mechanism of alpha2-adrenergic inhibition of sympathetic ganglionic transmission. Anesth Analg 1998;87(3):503-510

13 Sudheesh K, Harsoor S. Dexmedetomidine in anaesthesia practice: A wonder drug. ? Indian J Anaesth 2011;55(4):323-324

14 Guo TZ, Jiang JY, Buttermann AE, Maze M. Dexmedetomidine injection into the locus ceruleus produces antinociception. Anesthesiology 1996;84(4):873-881

15 Stoelting RK, Pharmacology and Physiology in Anaesthesia Practice. 3rd ed. Philadelphia, Pennsylvania: Lippincott-Raven Publishers; 1999 pp. 93-97

16 Elfawal SM, Abdelaal WA, Hosny MR. A comparative study of dexmedetomidine and fentanyl as adjuvants to levobupivacaine for caudal analgesia in children undergoing lower limb orthopedic surgery. Saudi J Anaesth 2016;10(4):423-427

17 Kannojia UK, Meena RK, Paswan AK, Meena K, Prakash S, Loha S. Comparison of caudal dexmedetomidine and fentanyl combined with bupivacaine in pediatric patients undergoing urogenital surgery. Anaesth Pain Intensive Care 2017;21(2):204-211

18 Jarineshin H, Fekrat F, Kargar Kermanshah A. Treatment of postoperative pain in pediatric operations: comparing the efficiency of bupivacaine, bupivacaine-dexmedetomidine and bupivacaine-fentanyl for caudal block. Anesth Pain Med 2016;6(5):e39495
19 Zeben KR, Qudaisat IY, Halaweh SA, et al. Comparison of caudal bupivacaine alone with bupivacaine with two doses of dexmedetomidine for postoperative analgesia in pediatric patients undergoing infra -umbilical surgery. Paediatr Anaesth 2015;25(9):883-890

20 Goyal V, Kubre J, Radhakrishnan K. Dexmedetomidine as an adjuvant to bupivacaine in caudal analgesia in children. Anesth Essays Res 2016;10(2):227-232

21 Sengupta S, Mukherji S, Sheet J, Mandal A, Swaika S. Caudalepidural bupivacaine versus ropivacaine with fentanyl for paediatric postoperative analgesia. Anesth Essays Res 2015;9(2): 208-212

22 Anand VG, Kannan M, Thavamani A, Bridgit MJ. Effects of dexmedetomidine added to caudal ropivacaine in paediatric lower abdominal surgeries. Indian J Anaesth 2011;55(4):340-346

23 Saini S, Patodi V, Sethi S, Jain N, Mathur P, Thada B, Comparison of caudal epidural clonidine with fentanyl as an adjuvant to ropivacaine $0.25 \%$ for postoperative analgesia in children undergoing various infraumbilical surgeries: a prospective randomized study. Ai-Shams J Anaesthesiol 2016;9(4):493-500

24 Khatavkar SS, Lonkar SS, Panchal PB, Thatte WS, Nagendra S, Tewari D. The efficacy of ropivacaine-fentanyl versus ropivacaine-clonidine for pre-emptive caudal anesthesia in children. Anaesth Pain Intensive Care 2016;20(1):54-58

25 Reddy M, Gangadharaiah R. A comparative clinical study between equal volumes and concentrations of clonidine and dexmeditomidine as adjuvants to $0.25 \%$ ropivacaine in pediatric caudal block for circumcision. J Evol Med Dent Sci 2014;3(10):2470-2477 